\title{
LIFTING MECHANISM USING HYDRAULIC CYLINDERS
}

\author{
Sahil Shinde, Shivraj Sapkal, Siddhesh Gavhane, Chetan Gudadinni \\ Pimpri Chinchwad college of engineering, Pune
}

\begin{abstract}
The main objective is to design product which will help us to load and unload goods into the goods carrier vehicles, so to reduce the labour work and increase the efficiency we are designing a product using hydraulic mechanism.
\end{abstract}

Keywords-Hydraulic cylinders, rollers, pillar

\section{INTRODUCTION}

We identified that people face many difficulties for loading unloading and stacking of the goods into the goods carrier vehicles. Most of the stacking work is done by the Laborers. Thus, it results in wastage of time, money and manpower. In our project we want to Design a LIFTING MECHANISM which can transport the goods easily with minimum human efforts.

\section{DESIGN SPECIFICATION}

To Fulfill our problem statement various Design were examined and tried to get The best in our design. While designing the portable lifting mechanism almost care was taken regarding the weight its usability, easy operation, so that it can be done by any operator by considering all this parameters we design various components and finally came up with a product, which we think will definitely be useful in industrial application

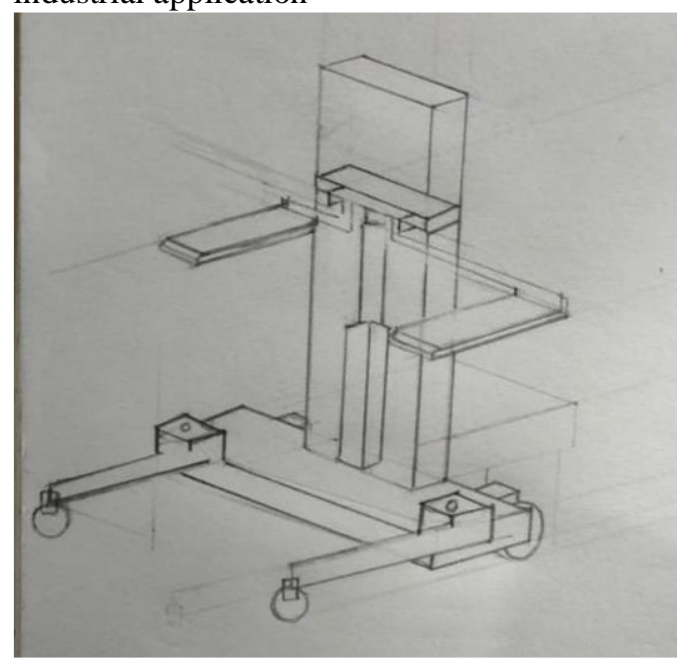

It is a fully detachable system right from the base, then the hydraulic cylinder holding pillar and the platform for the operator to stand on it are fully detachable.

Even while designing the arms, a unique element was added where slots are provided in both the lifting arms. The slots provided so that a plate can be inserted in the two arms and a proper plane surface can be provided whenever required. Also the two lifting arms slide sideways so that the distance can be adjusted according to the requirement of the load.

\section{COMPONENTS}

\section{- Detachable base}

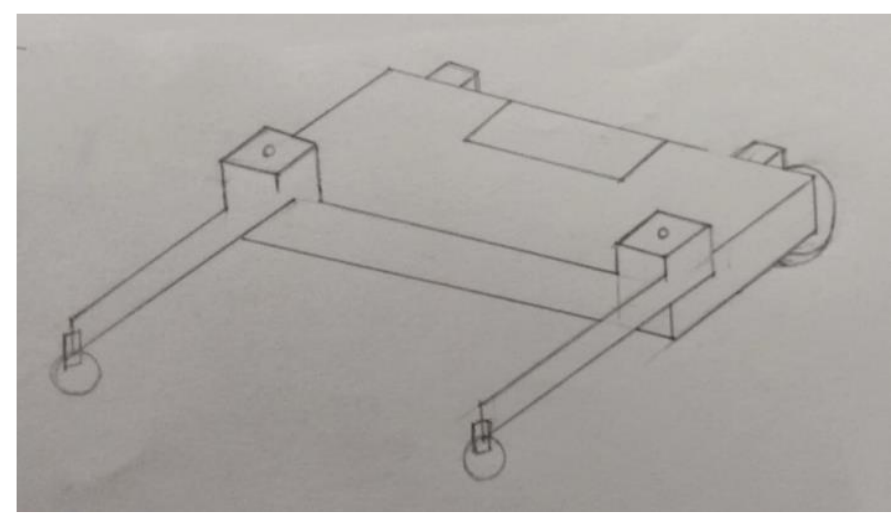

The base is one of the main component as all the mounting are done are done on the base itself. The hydraulic cylinders holding pillar, standing platform for operator are all mounted on the base. The two front wheel arms reach to the surface and don't get blocked by 2 front wheel arms.

- Hydraulic cylinder holding pillar

The hydraulic cylinder is fixed the pillar, the two lifting arms attached to the plate slide in the pillar and lifts the weight to a particular height. The standing platform is also given support by the pillar 


\section{International Journal of Engineering Applied Sciences and Technology, 2016 Vol. 1, No. 8, Pages 1-6 \\ Published Online June - July 2016 in IJEAST (http://www.ijeast.com)}

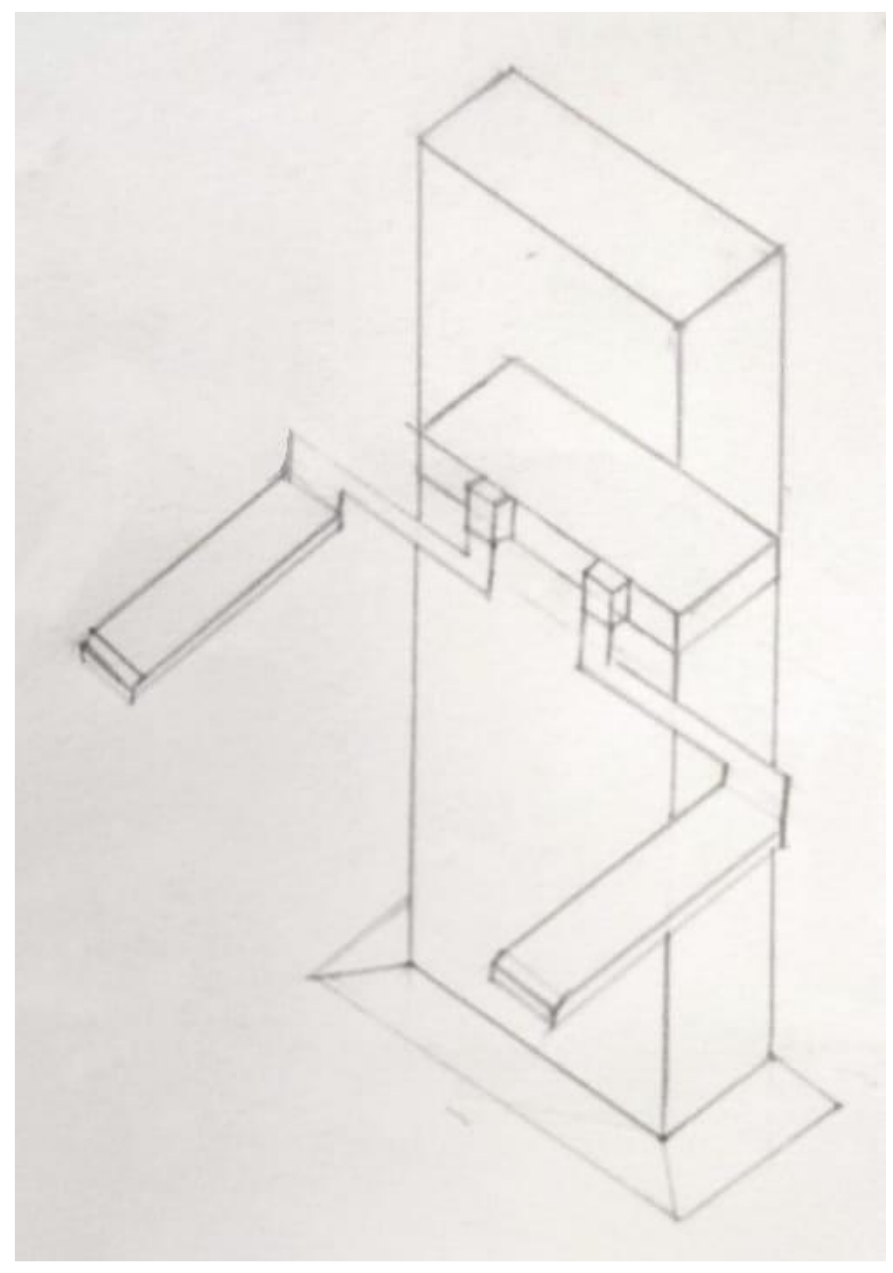

- Standing platform for counterbalance

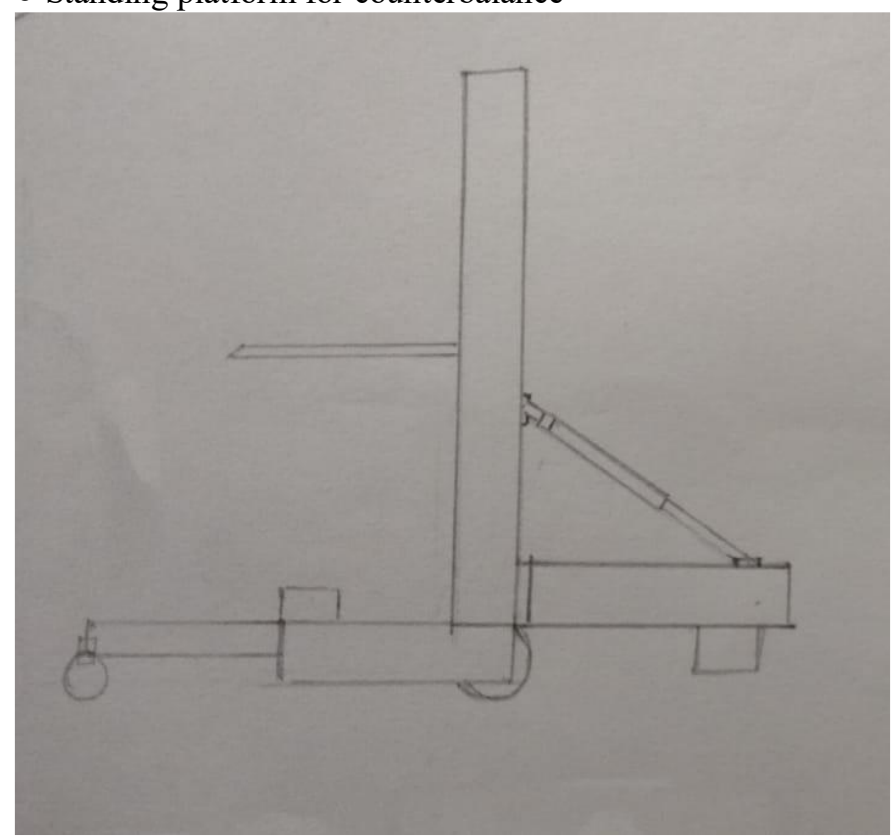

The standing platform is made foldable using small hydraulics and also it is removable. So it does not add up to the total weight of the mechanism. The main function of the standing platform supported by hydraulics is to act as a counter balance for the whole mechanism when the load is lifted to a particular height. The standing platform and the pillar is hold by small hydraulics strengths in this mechanism.

\section{Dimension:}

Base: $500 \mathrm{~mm} \times 950 \mathrm{~mm}$

Pillar: 275mm x 1400mm

Standing platform: 400mm x 800mm

\section{Material:}

Pillar: Load acts on pillar tends to break or cause bending the component. Stainless steel is used on the basis of strength, stiffness, plasticity and hardness.

Hydraulic cylinder: It is subjected to the compressive force which impose buckling and bending of component. Longitudinal and circumferential stress also generated because of internal compressive stress. Hence mild steel is a good option because of high ductility and hardness

Base platform: Whole assembly stability based on this therefore mechanical properties are needed like strength, hardness etc. so recommended material is mild steel.

\section{WORKING PRINCIPLE}

Hydraulic lift works on the principle of Pascal Law. The principle of transmission of fluid-pressure or Pascal Law is the principle in fluid mechanics that explain that the pressure applied anywhere in a confined incompressible fluid is transmitted equally in all directions throughout the fluid such that the pressure variations (initial differences) remain the constant. The common logic behind every hydraulic mechanism is very simple that is Force that's applied at one point is transmitted to another point using an incompressible fluid. The force is almost always multiplied in a process. A common hydraulic mechanism consists of two pistons and an oil-filled pipe connecting to them. In single acting cylinder the output force is devloped in only one direction when you feed oil or hydrauilc fluid into it through the inlet port it will extend exerting force and the piston will move upwards. In this case we are using hydraulic hand pump to provide pressurized fluid, hand pump are easy to use but we could alternatvely use an electric pump or air driven pump.

when the work is done you need to release fluid back into the tank. to do this needle valve is fitted into the hand pump, you open the valve the oil flows back into the tank and piston will drop. 


\section{International Journal of Engineering Applied Sciences and Technology, 2016 \\ Vol. 1, No. 8, Pages 1-6 \\ Published Online June - July 2016 in IJEAST (http://www.ijeast.com) \\ V. FUTURE SCOPE:}

- The machine can be used for domestic as well as commercial purpose.

- The machine can prove much helpful in industrial zones by lifting heavy metals, various equipment, scraps, etc and loading them to a particular destination.

- A LPG gas cylinder can be lifted or shifted to a desired location without moving the vehicle.

\section{CONCLUSION}

- The machine will be useful in lifting heavy weights eventually reducing man power to a greater extent.

- Hydraulic system installed provides flexibility to lift greater weight unlike pneumatic system.

- since the base (platform) is detachable it reduce weight of the machine and also helps in moving the weights to a different location using rollers.

- The bracket platform installed at the back of the machine eliminates the use of counter weights used in conventional machines.

- The rollers helps in moving the machine with easy turns and lock for rollers helps the machine to remain stationary

\section{REFERENCES}

1.Design and analysis of hydraulic scissor lift by FEA

Sabde Abhijit manoharrao, prof. jamgekar R.S.

2. Design of a New Load Lifting Mechanism- Research gate

3.Design \& Research of Large Height Lifting Mechanism for Ultra-Large Structures- Scientific.net. 